\title{
Family Coordination in Families who have a Child with Autism Spectrum Disorder
}

\section{Silvia Mazzoni, Christian Veronesi, Laura Vismara, Fiorenzo Laghi \& Diane Philipp}

Journal of Child and Family Studies

ISSN 1062-1024

J Child Fam Stud

DOI 10.1007/s10826-018-1191-4

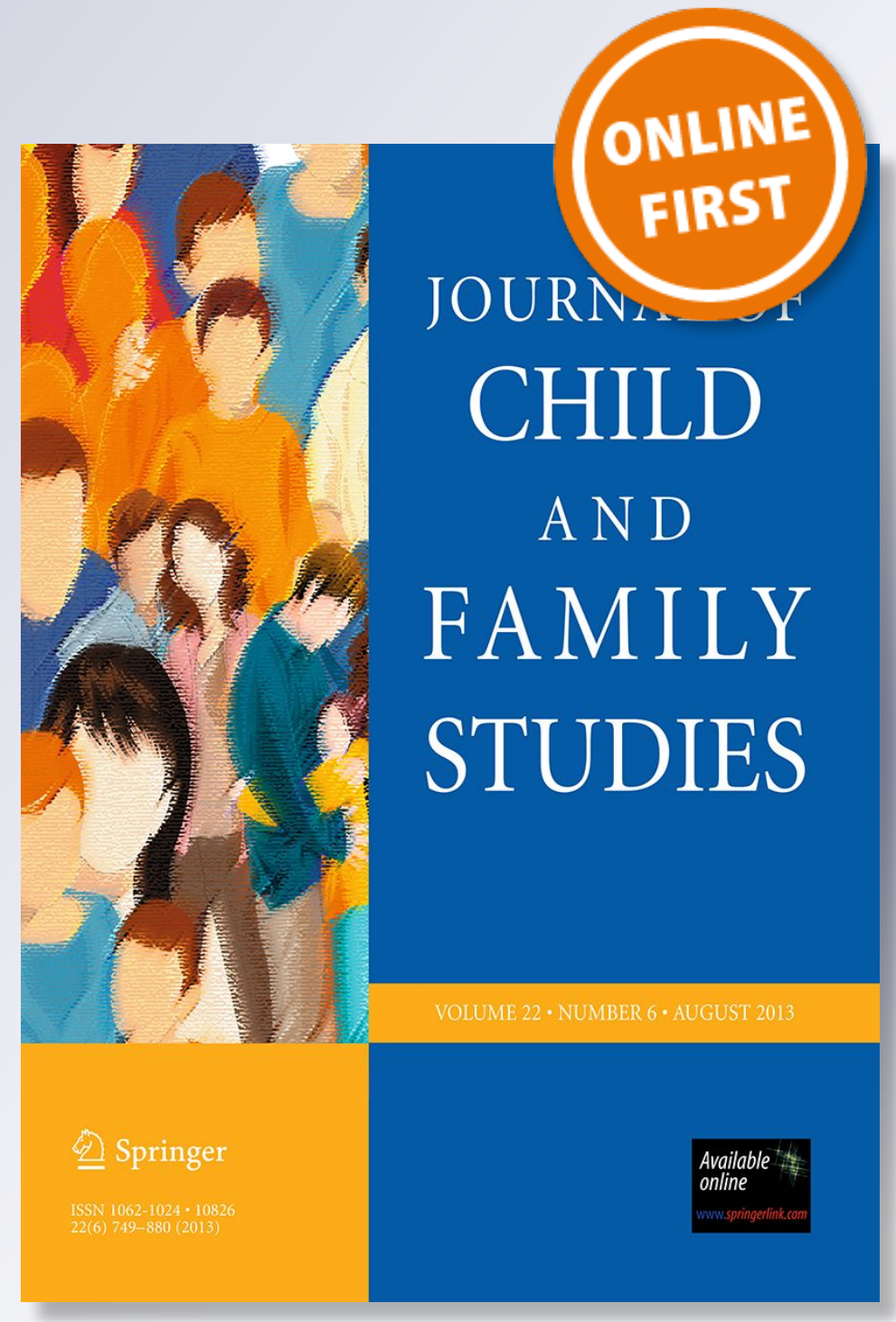

望 Springer 
Your article is protected by copyright and all rights are held exclusively by Springer Science+Business Media, LLC, part of Springer Nature. This e-offprint is for personal use only and shall not be self-archived in electronic repositories. If you wish to selfarchive your article, please use the accepted manuscript version for posting on your own website. You may further deposit the accepted manuscript version in any repository, provided it is only made publicly available 12 months after official publication or later and provided acknowledgement is given to the original source of publication and a link is inserted to the published article on Springer's website. The link must be accompanied by the following text: "The final publication is available at link.springer.com". 


\title{
Family Coordination in Families who have a Child with Autism Spectrum Disorder
}

\author{
Silvia Mazzoni $\oplus^{1} \cdot$ Christian Veronesi $^{1} \cdot$ Laura Vismara $^{2} \cdot$ Fiorenzo Laghi $^{1} \cdot$ Diane $^{\text {Philipp }}{ }^{3}$ \\ (c) Springer Science+Business Media, LLC, part of Springer Nature 2018
}

\begin{abstract}
Little is known about the interactions of families where there is a child with autism spectrum disorder (ASD). The present study applies the Lausanne Trilogue Play (LTP) to explore both its applicability to this population as well as to assess resources and areas of deficit in these families. The sample consisted of 68 families with a child with ASD, and 43 families with a typically developing (TD) child. With respect to the global score for family coordination there were several negative correlations: the more severe the symptoms (based on the child's ADOS score), the more family coordination was dysfunctional. This correlation was particularly high when parents had to play together with the child. In the parts in which only one of the parents played actively with the child, while the other was simply present, some families did achieve scores in the functional range, despite the child's symptom severity. The outcomes are discussed in terms of their clinical implications both for assessment and for intervention.
\end{abstract}

Keywords Intersubjectivity $\cdot$ Family coordination $\cdot$ Autism spectrum disorders $\cdot$ Developmental disorders $\cdot$ Observational method

\section{Introduction}

Autism Spectrum Disorder (ASD) is a heterogeneous neurodevelopmental disorder that affects not only the individual, but also has significant impact on the families of those with the disorder (Cadman et al. 2012; Dykens 2015; Ekas et al. 2010; Giallo et al. 2013; Hoefman et al. 2014; Laghi et al. 2018; Pottie and Ingram 2008). Moreover, family functioning is thought to have a reciprocal relationship with ASD symptomatology in children with this disorder (Kelly et al. 2008; Karst and Van Hecke 2012), where not only do the child's symptoms impact on the family, but difficulties in family functioning can exacerbate the child's ASD symptoms and lead to poorer outcomes in treatment

Silvia Mazzoni

silvia.mazzoni@uniroma1.it

1 Faculty of Medicine and Psychology, Sapienza Università di Roma, Rome, Italy

2 Department of Educational Sciences, Psychology, PhilosophyUniversity of Cagliari, Cagliari, Italy

3 Hincks-Dellcrest Centre, Faculty of Medicine, University of Toronto, Toronto, ON, Canada programs. Some have now pushed for more consistent and rigorous inclusion of family functioning measures when assessing treatment programs for ASD (Karst and Van Hecke 2012; Lord et al. 2005), with the hopes of being better able to tailor treatments to individual cases and families (Vivanti et al. 2014). Of the limited research that does exist on family functioning, the measures used are questionnaires and self-reports, looking at the parent's bond with the child, family functioning, the marital relationship, and even sibling functioning (Gau et al. 2012; Hoffman et al. 2009; Kelly et al. 2008; Montes and Halterman 2007; Rao andBeidel 2009). In their review of the literature, Karst and Van Hecke (2012) point out two significant limitations of such measures in the ASD population. Many of the parents may themselves struggle with sub-clinical symptoms of ASD (Losh et al. 2008; Sucksmith et al. 2011) and therefore may not be the best reporters on family functioning or even on their child's symptoms. In addition, many of the parents of children with ASD struggle with other mental health difficulties, such as anxiety and depression (e.g. Davis and Carter 2008; Ekas et al. 2010; Carter et al. 2009) that may also affect their reporting of symptoms in the child and in the family. For these reasons, it is critical that we have observational tools to assess and follow treatment outcomes in children with ASD (Karst and 
Van Hecke 2012; Lord et al. 2005), particularly where the treatment relies heavily on parent involvement.

Indeed, there have been several studies that have looked at parent-child interactions, including free-play scenarios (Duvekot et al. 2017) as well as the Strange Situation (Ainsworth et al. 1978), a procedure for assessing the child's attachment (Rutgers et al. 2004; Oppenheim et al. 2009). These studies, however, have been done in the context of dyads (mother-child; father-child), typically the primary caregiver and the child with ASD. But children develop in the context of multiperson relationships, even more so than dyadic ones (Fivaz Depeursinge et al. 2004) and certainly dyadic observations cannot tell us the whole story of the family. Moreover, to our knowledge, there are currently no observational tools of family functioning in the ASD population, that capture coparenting, or the degree to which a couple can coordinate their efforts with respect to parenting.

The Lausanne Trilogue Play paradigm (LTP) is an observational tool that was initially developed for the infant and preschool context to understand family functioning from its earliest stages (Fivaz Depeursinge and Corboz Warnery 1999). It has now been used in a variety of settings as well as ages and stages of family development to understand the influence of family interactions on the child's development (McHale et al. 2008; Favez et al. 2006; Fivaz Depeursinge and Favez 2006; Phelps et al. 2013; van Steijn et al. 2014). Given our understanding of the role of the family on development in normative populations, and our ability to assess the whole family using the LTP, one primary aim of this study was to determine the feasibility and applicability of this tool for assessment in the ASD population.

Of particular interest, research using the LTP with nonclinical community samples has shown that by age 5, children growing up in well-coordinated families appear to have better skills managing multiperson communication (Favez et al. 2012) and perform better on Theory of Mind tasks (Lonigro et al. 2017). Theory of mind refers to the capacity of an individual to understand the intentions, beliefs, and wishes of others (Baron-Cohen 1991), and is a central deficit in ASD. While theory of mind typically refers to a biological or cognitive capacity, Fonagy and colleagues have described children as learning to understand their own and others' minds within the context of their early relational environment, typically their families. They define this as reflective capacity, the ability to interpret human behaviour as stemming from the intentions, wishes, fears, or expectations of others. Reflective capacity appears to be passed from parent to child, laying the foundation by which children come to perceive themselves and others as intentional agents that are separate not only physically but also mentally (Fonagy et al. 1991; Fonagy and Target 1997).
This capacity emerges within an attachment relationship, a bidirectional bond, where parents with strong reflective capacity are attuned and responsive to the child's cues. In the context of ASD, symptoms may impact directly on the evolution of any given dyad's attachment relationship. In other words, some children with ASD may give confusing or no cues to their parents, and in turn, their parents will vary on their capacity to perceive and respond appropriately to these cues given their own reflective capacity and social skills (Van IJzendoorn et al. 2007).

Others have referred to the bidirectional nature of relationships as intersubjectivity (Stern 1985). Trevarthen and Aitken (2001) have described autism as a biological impairment of affective contact and intersubjectivity (Trevarthen and Aitken 2001). Several studies have now shown an impairment at the level of intersubjectivity in the context of ASD. Specifically, these children do tend to fail to make appropriate overtures to their parents that would invite the parents into an interaction. This deficit in the child appears to then negatively impact the parent's capacity to scaffold the child's social skills, resulting in an additional risk to the biological vulnerability already there (Davis and Carter 2008; Hastings and Brown 2002).

Several studies have now explored the struggles that people with autism spectrum disorder have in their interactions as a result of this deficit (Oberman and Ramachandran 2007; Frith 1996; Baron-Cohen 1991). The intersubjective system plays a significant role in fostering our understanding of others' intentions and goals (Fishman Fishman et al. 2014; Libero et al. 2014; Marsh and Hamilton 2011), and the ability to share affect and attention within the family context may promote more successful communication with a social partner (Adamson and Bakeman 1985; Kasari et al. 1990; Sigman and Ruskin 1999).

Given that we can now explore interactions at the level of the whole family, the aim of this study was to investigate collective intersubjectivity as observed through shared affect and attention within families with a child with autism.

To approach this question, we used a version of The Lausanne Trilogue Play (LTP; Fivaz Depeursinge and Corboz Warnery 1999) adapted for preschool and schoolage children as well as for clinical contexts (Malagoli Togliatti and Mazzoni 2006). In an LTP the family is seated in a triangular configuration and asked to play in four parts. First one parent plays with the child, while the other parent is in the third-party position, simply present. In part two, the parents reverse roles. All three play together in part three. Finally, in part four, the parents engage with each other and the child is in the third-party position. The LTP requires parents to cooperate and coordinate to carry out the shared task, and for the child to be able to play with the parents' guidance. In the context of the LTP, the "family alliance" is then defined as the degree to which the family members can 
coordinate in this shared play task, from most to least coordinated.

Given how little is understood about family interactions in the context of a child with ASD, one goal of the present study was to assess the feasibility of the LTP in this context. Could the families with an ASD child tolerate the task and would the findings be codable? If the former was possible, we would then want to compare families with a child who has ASD to a control group with typically developing children, using the LTP. Thus, our aim was also to describe any differences in patterns between the two groups. More specifically, in this study we aimed first to explore the relationship between the degree of family coordination and the severity of the child's ASD symptoms. If the family could participate in the task, we anticipated that the intersubjective components of the task, i.e. joint focus and affect sharing, would be most challenging for families with a child who has ASD. In particular, we expected parts 3 and 4 of the LTP to be the most difficult for them, as in part 3 the child must manage a 3-person interaction. In part 4, we hypothesized a bimodal response. Some of these children would perhaps find something of interest to preoccupy them while the parents discussed, whereas others might struggle with the inattention.

By having both parents in the assessment we had the opportunity to see the roles of fathers and mothers as well as the coparenting relationship. The latter is a unique component of the marital relationship, in which parents work together, or alternatively, struggle against each other when it comes to child rearing (McHale 2007). We expected that parents most able to respond in a coordinated manner would be more successful in the task, regardless of the diagnosis.

\section{Method}

\section{Participants}

The sample consisted of 68 families with a child with ASD (59 males and 9 females; Mean age $=86.12$ months; $\mathrm{SD}=$ 41.83), who were recruited from a rehabilitation center (CRC Balbuzie) in Rome. The age range was from 36 to 120 months. Exclusion criteria included children with severe intellectual disability or frequent, uncontrolled aggression (as determined by the referring agencies). Some children had only recently received the diagnosis of ASD, while others were already in treatment. The control group ( $n=43$ families) consisted of families with a typically developing (TD) child (15 males and 28 females; Mean age $=98.74$ months; $\mathrm{SD}=37.48$ ). The age range was from 30 to 132 months. For the TD arm, inclusion criteria required being at the expected grade level in school, no previous requests for assessment or treatment for a Learning Disability or any neuropsychiatric or neurodevelopmental disorder.

\section{Procedure}

Children scoring high on autism spectrum symptoms in the Autism Diagnostic Observation Schedule (ADOS) (Lord et al. 2000)] [mean(SD) 12.71 (4.94)] were included in the study. Diagnoses were made by the rehabilitation center's team consisting of a child psychiatrist and psychologists. Recruitment was carried out at different points in the children's assessments. Families were referred to the study by their clinicians. All were offered a feedback session about their family functioning, based on their LTPs. The Department of Dynamic and Clinical Psychology, Sapienza University recruited TD families through a student project entitled "Family Resources and Child Development" where parents were asked to participate in a study of family play with their children.

All procedures performed in studies involving human participants were in accordance with the ethical standards of the institutional and/or national research committee and with the 1964 Helsinki declaration and its later amendments or comparable ethical standards. Approval from the University Research Ethics Board was obtained before data were collected for the current study.

\section{Measures}

The Lausanne Trilogue Play (LTP; Fivaz Depeursinge and Corboz Warnery 1999), as described in the introduction, is a semi-structured observational procedure used to study family interactions in a three-way relationship. The family is asked to sit around a table and play with Duplo $^{\circledR}$ as well as other familiar material that can be easily manipulated by the children (toy animals, blocks). Parents are asked to help their child play with the toys in the four parts of an LTP. One deviation from the traditional LTP format is that we asked the parents to "signal" one another for each transition from one part to the next. We made this choice to be clear about who initiated the transition and to observe the clarity and ease of the transition itself. As well, if the child found it difficult to sit at the table, the family could choose to sit on the floor, still in a triangular configuration. The parents are given the guidelines of 15-20 minutes for the whole play sequence, but can decide how much time to play together in each part. The overall duration is slightly longer than the Lausanne group's LTP (10-15 minutes), given the child's age. Time spent in each part and for the whole play is scored $(0=$ inappropriate $[\leq 2$ or $\geq 10$ minutes $] ; 1=$ partially 
appropriate [2.1-3.9 minutes or 7.9-9.9 minutes], and $2=$ appropriate [between 4 and 7 minutes]). As with clinical LTPs (Fivaz-Depeursinge and Philipp 2014), we left the family free to decide which parent plays first. Finally, in the families with a child who has ASD, it seemed crucial to evaluate parental capacity to cooperate and to repair miscoordinations separately from the child's performance, which may be affected by the child's specific impairment. We therefore created scores for each individual family member, as well as a global family system score on the four functional levels of the LTP (participation; organization; focalization and affective contact; see below). The same procedure and coding system was applied to all families of the sample.

Family coordination is evaluated - at a dimensional level -through four different functional levels (participation, organization, focalization and affective contact). These components are thought to underlie important psychological and interpersonal processes that comprise family interactions. The functional level of participation assesses the extent to which each member is included and self-includes within the play. Even as a third party, there is a minimum degree of participation expected in a social interaction. As a result, this function needs to be constant, and therefore assessed, across all four parts of the play. Organization assesses whether each member maintains their assigned roles in the four parts of the play. In each part, it is expected that the parents be supportive and guide the child and not vice versa, however, their functions in the roles will change across the play task. In the first two parts the parents alternate in the active or third party role, whereas in the third part they are both active with their child. Finally, in the fourth part, the child is the third party and the parents have their own discussion yet remain somewhat attentive to their child should the child need them; in other words, maintaining a clear but flexible boundary (Minuchin 1974; Fivaz-Depeursinge and Philipp 2014). The functional level of focalization assesses the degree to which everybody is paying attention to the play regardless of their role; it is consequently evaluated across all parts. The maintenance of joint attention is key in being able to share significant meanings (Wynne 1984) as well as in sharing affects. Affective contact assesses whether each member of the family appears relaxed and playful throughout the procedure, as well as whether they encourage and appreciate the other members, and contribute to the overall experience. The evaluation of this function is also present across all parts.

The coding is based on video observations of the family interaction by two independent and reliable judges, who were blind to the goals of the research. They assigned scores from 0 (not appropriate) to 2 (appropriate) to each member of the family in each part and with respect to each function.
Co-score reliability on the LTP was established at $90 \%$ before data collection began. Reliability for the two coders was calculated (mean Cohen $K$ Index $=.83$ ).

The Autism Diagnostic Observation Schedule. The Autism Diagnostic Observation Schedule (ADOS; Lord et al. 2005) is a semi-structured assessment of communication, social interaction, and play (or imaginative use of materials) for individuals suspected of having an autism spectrum disorder. The ADOS consists of four modules, each of which is appropriate for children and adults of differing developmental and language levels, ranging from nonverbal to verbally fluent. The examiner selects the module that is most appropriate for the child or adult based on their expressive language level and chronological age. The goal of the ADOS is observation of social behaviour and communication, and it provides standardized contexts in which interactions occur (Lord et al. 2000). Participants were included in the study when the ADOS score met clinical criteria for $\operatorname{ASD}(>=7)$.

\section{Data Analyses}

MANOVAs were conducted to verify group differences on family function dimensions and on phases. Partial etasquared values were calculated as a measure of effect size, and results were interpreted using Cohen's (1988) guidelines for determining small (.01), medium (.06), and large (.14) effects.

An ANOVA was conducted to verify group differences on family coordination. Freidman's chi-square and, subsequently, pairwise comparisons with Wilcoxon signed-rank were used to verify whether there were differences in the four phases for the clinical and control group.

Bivariate correlations, using the Pearson productmoment, among the key variables of the family coordination and severity of the child's ASD, as evaluated by ADOS, were computed. All statistical analyses were performed with SPSS 24 for Windows.

\section{Results}

Preliminary analyses revealed no univariate outliers. According to Curran et al. (1996), the skewness and kurtosis of dimensions analyzed by LTP were within the range proposed (values less than $|2|$ for univariate skewness and kurtosis). Thus, these variables were used for the following analyses:

A one-way analysis of variance (ANOVA) confirmed no statistically significant differences between the groups in terms of age $(p>.05)$. Furthermore, a $X^{2}$ test confirmed statistically significant association between group and gender, as reported in Table 1. This high proportion mirrors the 
Table 1 Demographic characteristics of the sample

\begin{tabular}{|c|c|c|c|c|c|}
\hline \multirow[b]{2}{*}{ Child characteristics } & \multicolumn{2}{|c|}{$\begin{array}{l}\text { ASD group } \\
(N=68)\end{array}$} & \multicolumn{2}{|c|}{$\begin{array}{l}\text { TD group }(N \\
=43)\end{array}$} & \multirow[b]{2}{*}{$X^{2}$} \\
\hline & $\mathrm{f}$ & $\mathrm{f} \%$ & $\mathrm{f}$ & $\mathrm{f} \%$ & \\
\hline Gender & & & & & $31.91 *$ \\
\hline Male & 59 & 86.76 & 15 & 34.9 & \\
\hline \multirow[t]{2}{*}{ Female } & 9 & 13.24 & 28 & 65.1 & \\
\hline & $M$ & SD & $M$ & SD & $\mathrm{F}$ \\
\hline Age expressed in months & 86.12 & 41.83 & 98.74 & 37.48 & 2.60 \\
\hline \multicolumn{6}{|l|}{ Family characteristics } \\
\hline Mothers age & 38.38 & 4.95 & 39.51 & 5.00 & 1.35 \\
\hline Fathers age & 41.95 & 6.14 & 43.49 & 6.19 & 1.61 \\
\hline Socio-economic status & 46.31 & 20.05 & 49.17 & 18.74 & .56 \\
\hline \multicolumn{6}{|l|}{ ADOS } \\
\hline Total score & 12.71 & 4.94 & - & - & \\
\hline
\end{tabular}

$* p<.001$

male-female gender discrepancy in the general population of ASD children. The mean socio-economic level of the families was calculated with Hollingshead's index (Hollingshead 1975), based on two main variables (parents' education level and occupation). The demographic characteristics of the sample are reported in Table 1. All families recruited, including those with a child who had ASD, were able to complete the LTP task and are therefore included in the analyses

\section{Relationship between Family Coordination and Severity of the Child's ASD}

There was no association between the severity of ADOS scores and the individual parental scores on the LTP, however, the more severe the child's symptoms, as assessed by means of the ADOS, the lower the family coordination score was $(r=-.46 ; p .<0,01)$. More specifically, the global score for families on the LTP was significantly negatively correlated with ASD symptomatology $(r=-.52 ; p<$ $0,01)$. Participation was also associated with child impairment $(r=-.34 ; p<0.01)$. The characteristics of the children with ASD seemed to be negatively linked to their participation $(r=-.31 ; p<0.01)$, as well as the organization of these families $(r=-.34 ; p<0.01)$, affecting the play with the mothers $(r=-.45 ; p<0.05)$ and the fathers $(r=$ $-.41 ; p<0.05$ ), irrespective of the parents' roles as active or third party. In addition, the severity of the child's symptomatology seemed to compromise both the "three together" part $(r=-.41 ; p<0.05)$, and the last part of the LTP, when the parents spoke to one another $(r=-.41 ; p<$ 0.05).
Table 2 Mean scores of groups for global family coordination, and functions

\begin{tabular}{llllllll}
\hline & \multicolumn{2}{l}{$\begin{array}{l}\text { ASD group } \\
(N=68)\end{array}$} & & \multicolumn{2}{l}{$\begin{array}{l}\text { TD group } \\
(N=43)\end{array}$} & & \\
\cline { 2 - 3 } & $M$ & SD & & $M$ & SD & $\mathrm{F}_{(1,108)}$ & Partial $\eta^{2}$ \\
\hline Function (Family) & & & & & & \\
Participation & 6.28 & 1.90 & 7.02 & 1.24 & $5.18^{*}$ & .04 \\
Organization & 3.50 & 1.53 & 4.26 & 1.62 & $6.14^{*}$ & .05 \\
Focalization & 3.57 & 1.81 & & 4.86 & 1.58 & $14.60^{* *}$ & .12 \\
Affective contact & 2.16 & 1.64 & 3.72 & 1.24 & $28.62^{* *}$ & .20 \\
Family & & & & & & \\
Coordination & & & & & & \\
Global score & 20.15 & 6.75 & 25.33 & 5.18 & $18.40^{* *}$ & .14 \\
\hline
\end{tabular}

Partial eta-squared values were calculated as a measure of effect size, and results were interpreted using Cohen's (1988) guidelines for determining small (.01), medium (.06), and large (.14) effects $* p<.05 ; * * p<.01$

\section{Functional Levels and Family Coordination in Families with a Child Diagnosed with ASD}

We conducted a MANOVA on the different components of family coordination, holding the different functional levels (participation, organization, focalization and affective contact) as dependent variables and the group (families with a child diagnosed with ASD vs. families with typically developing children) as the independent variable. The analysis revealed a main effect for group, $\lambda=0.77, F(4$, 106) $=7.71$, partial $\eta^{2}=.22, p=.0001$. Results from the univariate tests (ANOVAs) revealed that the two groups differed on the subscales of Participation, Organization, Focalization, and Affective contact. For all dimensions, families with a child diagnosed with ASD obtained lower scores than families with typically developing children. Additionally, the ANOVA for Coordination revealed that the two groups differed on total scores, where families with a child diagnosed with ASD obtained lower scores than families with typically developing children (Table 2).

Mean scores, differentiated for children and parents by functions are reported in Table 3.

\section{Quality of Family Interactions in the Four Phases of LTP}

We conducted a MANOVA on the different phases (mother/child + father; father/child + mother; three together; mother/father + child). The analysis revealed a main effect for group, $\lambda=0.79, F(4,98)=6.31$, partial $\eta^{2}=.20$, $p=.0001$. Results from the univariate tests (ANOVAs) revealed significant differences for each of the phases, where families with typically developing children obtained higher scores than families with a child diagnosed with 
ASD, as reported in Table 4. Additionally, significant differences were found for the four phases in the clinical (Freidman's chi-square $=45.86 ; \quad \mathrm{gdl}=3 ; \quad p<.001$ ) as compared to the control group (Freidman's chi-square $=$ 14.57; $\mathrm{gdl}=3 ; p<.01)$. Follow-up pairwise comparisons using a Wilcoxon signed-rank test for the clinical group showed that mean scores were also significantly lower in phase 3 and phase 4 than phases 1 and 2 that did not significantly differ from each other $(p>.05)$. Wilcoxon signedrank test for the control group, showed that mean scores were also significantly lower in phase 4 than other phases.

\section{Discussion}

The first aim of this study was to explore the applicability of the LTP in the specific context of autism spectrum disorder

Table 3 Mean scores of groups for functions by participants

\begin{tabular}{llllll}
\hline & \multicolumn{2}{l}{ ASD group $(N=68)$} & & \multicolumn{2}{c}{ TD group $(N=43)$} \\
\cline { 6 - 6 } & $M$ & SD & & $M$ & SD \\
\hline Participation & & & & \\
Child & 6.54 & 1.89 & & 7.70 & .71 \\
Father & 7.13 & 1.05 & & 7.42 & .93 \\
Mother & 7.15 & 1.14 & & 7.53 & .74 \\
Organization & & & & \\
Child & 4.51 & 1.86 & 5.95 & 1.23 \\
Father & 5.06 & 1.66 & 4.95 & 1.95 \\
Mother & 5.00 & 1.64 & 5.33 & 1.38 \\
Focalization & & & & \\
Child & 4.12 & 2.13 & 6.09 & 1.57 \\
Father & 5.21 & 1.57 & 5.37 & 1.50 \\
Mother & 5.25 & 1.77 & 5.51 & 1.49 \\
Affective contact & & & & \\
Child & 2.81 & 1.86 & 4.81 & 1.03 \\
Father & 3.22 & 1.49 & 4.16 & 1.56 \\
Mother & 3.63 & 1.48 & 4.47 & 1.20 \\
\hline
\end{tabular}

(ASD). All the families were able to complete the task, including those where the child had a diagnosis of ASD. In the majority of families, all three members were successfully included in the play. While some parents initially had reservations about the task, most of the children in some way were able to join in the shared play task.

Our next question was whether the families with an autistic child look different on an LTP and whether there is a relationship between family functioning and the severity of the child's ASD symptoms. We use the degree to which a family can achieve participation of all members, organization, joint focalization, and affective contact to create the score of global family coordination. In our study, families who had a child with ASD had lower family coordination scores, as compared with the families with typically developing children (TD). If we consider family coordination as a measure of the intersubjective experience, again referring especially to the capacity to engage in joint focus and affect sharing, then the LTP can capture this deficit in the families of children with ASD as compared to those with TD children.

Of note, several families of children with ASD did display certain resources, both in fostering participation in a shared experience and in respecting one another's roles. As well, several of the parents managed their children's symptoms and were thereby successful at attaining acceptable levels of participation and organization, albeit with great effort. Specifically, these parents were supportive of one another during the parts and could show warmth and positive reinforcement towards the child throughout the play. Within this encouraging and loving climate, these children were able to join the experience of a pleasant, shared task. What stands out is this subset of parents who were able to coordinate with one another in navigating the task and encouraging their child's participation, which may have clinical implications (see below).

Unlike family coordination, there was no association between the severity of the ADOS scores and the individual parental scores on the LTP. Our findings correspond with

Table 4 Mean scores of groups for phases

\begin{tabular}{|c|c|c|c|c|c|c|}
\hline & \multicolumn{2}{|c|}{ ASD group $(N=68)$} & \multicolumn{2}{|c|}{ TD group $(N=43)$} & \multirow[b]{2}{*}{$\mathrm{F}_{(1,108)}$} & \multirow[b]{2}{*}{ Partial $\eta^{2}$} \\
\hline & $M$ & SD & $M$ & SD & & \\
\hline \multicolumn{7}{|l|}{ Phases of the play } \\
\hline Phase 1 . Mother and child play & 5.89 & 179 & 6.92 & 1.48 & $8.99 *$ & .08 \\
\hline Phase 2. Father and child play & 5.63 & 1.89 & 6.92 & 1.36 & $13.54^{*}$ & .12 \\
\hline Phase 3. Family/triadic play & 5.08 & 2.25 & 6.39 & 1.33 & $10.79 *$ & .09 \\
\hline Phase 4 . Parental dyad play & 3.71 & 2.48 & 6.00 & 2.10 & $22.83 *$ & .18 \\
\hline
\end{tabular}

Partial eta-squared values were calculated as a measure of effect size, and results were interpreted using Cohen's (1988) guidelines for determining small (.01), medium (.06), and large (.14) effects

$* p<.001$ 
previous research on dyads that did not find a correlation between severity of ASD symptoms and parental sensitivity or capacity to see things from the child's point of view (Oppenheim et al. 2009; Van IJzendoorn et al. 2007). By having both parents present, we also found that the symptoms of ASD did appear to affect the functioning at the level of the family.

We next looked at the various components of the global family coordination score. As one would expect, focalization, the ability of all three family members to focus on the activity, including when in the third-party position, seemed particularly difficult for the ASD families. In these families both the parents and the child struggled to pay attention to one another's actions or to build a shared, coherent, and fluid narrative during play.

Similarly, with respect to affective contact, there were lower scores among ASD families. It follows that to be able to have affective contact, each partner must be open to sharing their own positive emotions with all other participants (McHale 2007). When we code for affective contact, the focus is on facial expressions, voice tonality, gaze exchanges, and nonverbal behaviours that convey affect. These features are notably impaired in individuals with Autism Spectrum Disorder (Vivanti et al. 2014). As a result, the parents' experience may be compromised as they cannot receive verbal and nonverbal affective feedback from their child. In other words, there may be a vicious cycle where the child's difficulties in social interactions may negatively affect the parents and their capacity to scaffold the child (Trevarthen and Aitken 2001; Rogers et al. 2012).

With respect to the four parts of the play, we anticipated that the third part of the LTP-when the child needs to participate in a three-way interaction-would be particularly challenging. While overall, the parents in the ASD group could coordinate such that their children were able to participate in the play, these families tended to struggle with sharing focus and affect. While these challenges might well be due to the child's disorder, we cannot preclude the possibility that the parents' own capacities for joint focus and affect sharing as contributing. Regardless, further studies are needed to better understand how these factors interact, including the evaluation of the parents' cognitive and psychological functioning.

In the fourth part of the LTP the child must tolerate his parents having their own interaction, and play independently. A family was coded as having a problematic fourth part when the child tried to be included in the interaction between the parents, and the parents, in turn, were not able to redirect the child or paid too much attention to the demands. The ASD subgroup, compared to TD families, encountered more difficulties in carrying out this fourth part. For some families where the child had an ASD diagnosis, the fourth part did not take place at all. The children were not able to play on their own, and instead drew the parents' attention away from their task of talking with one another. Of note, in the families with TD children, the majority of parents were able to create a clear boundary in part 4 , only attending to their child if necessary. Some families with a TD child also struggle with part 4 and it is certainly more common in clinical families as well as in the context of divorce and conflict (Carneiro et al. 2006; McHale 2007; Favez et al. 2012; Fivaz Depeursinge and Philipp 2014). Our findings are therefore consistent with other clinical samples.

In families where there is an ASD diagnosis, there is the potential for an interaction between the child's engagement style and the coparenting styles and family coordination overall. Problems in coparenting and family coordination can therefore be considered an additional risk factor for children with ASD. Our results point to the feasibility and importance of assessing families with both parents present when there is a child who has ASD.

Using a normative sample, Marcu et al. (2016) recently examined insightfulness in the context of the LTP. Here insightfulness refers to the degree to which a parent can coherently describe the motivations underlying their child's behaviour, and are open to new information that may contradict those underlying assumptions about their child (Oppenheim and Koren-Karie 2013). Not surprisingly they found that when both parents score high in insightfulness the family's coordination is rated as high on the LTP. If both parents scored low on insightfulness, problematic scenarios played out in the LTP. However, even if just one parent scored low on insightfulness, the LTP appeared less coordinated as well. Adding the child's deficits to the mix further complicates the picture, and future research might explore the question of parental insightfulness, or reflective function, as another mediating factor in this disorder, particularly in the context of coparenting.

Finally, we were interested in the idea of having two parents participating in this assessment procedure as, while researchers have explored the maternal experiences in the ASD population (Taylor and Warren 2012; Griffith et al. 2015), our study deepens our understanding of the role of fathers in these families. More specifically, we found that a large proportion of fathers in the TD families were capable of guiding and supporting their children, following their initiatives and interests, and creating a positive affective climate. In the ASD families, the fathers appeared to take great effort to guide and support their children, however, at a clinical and qualitative-observational level, they were primarily focused on the children's performance, rather than on developing a positive emotional environment. Again, we would propose that these data underscore the importance of further research involving both parents and even the whole family system in evaluations of children with ASD. 


\section{Limitations}

Our study does present some limitations. First, recruitment was carried out at different points in the children's assessments. Some families had just received the diagnosis while others had already started treatment. Furthermore, the age range of the children was broad. While there was no statistically significant effect for age, the developmental stage of the various children is likely of clinical relevance in terms of developing interventions. In future, it would also be useful to have a standardized evaluation of the parents' psychological and cognitive functioning as this may be another contributing factor. Parental qualities were not specifically measured in this study, however our results showing that parents struggled with focus and affect sharing corroborate and extend earlier findings that the parents of these children can have features of the disorder as well (Losh et al. 2008; Sucksmith et al. 2011). Nevertheless, future research in this area could include assessment of parental functioning, particularly as it pertains to these factors.

Further work in this area will help us to better understand the role the LTP can play both in family assessments for children with ASD as well as for treatment planning and direct intervention via video feedback.

Author Contributions SM, CV and LV: designed the study. SM and CV: executed the study. FL: analyzed the data and wrote part of the results. SM, CV, FL, and LV: collaborated with the design and writing of the study. SM, CV, DP, LV, FL: collaborated in the writing and editing of the final manuscript.

\section{Compliance with Ethical Standards}

Conflict of Interest The authors declare that they have no competing interests.

Ethical Approval All procedures performed in studies involving human participants were in accordance with the ethical standards of the institutional and/or national research committee and with the 1964 Helsinki declaration and its later amendments or comparable ethical standards. Approval from the Sapienza, University of Rome, Research Ethics Board, Department of Dynamic and Clinical Psychology was obtained before data were collected for the current study.

Informed Consent Informed consent was obtained from the parents of all individual participants included in the study.

\section{References}

Adamson, L., \& Bakeman, R. (1985). Affect and attention: Infants observed with mothers and peers. Child Development, 56, 582-593.

Ainsworth, M., Blehar, M., Waters, E., \& Wall, S. (1978). Patterns of Attachment. New York: Hillsdale, Erlbaum.

Baron-Cohen, S. (1991). Theory of mind in normal development and autism. Prisme, 34, 174-183.
Cadman, T., Eklund, H., Howley, D., Hayward, H., Clarke, H., \& Findon, J. et al. (2012). Caregiver burden as people with autism spectrum disorder and attention-deficit/hyperactivity disorder transition into adolescence and adulthood in the United Kingdom. Journal of the American Academy of Child and Adolescent Psychiatry, 51(9), 879-888.

Carneiro, C., Corboz-Warnery, A., \& Fivaz-Depeursinge, E. (2006). The Prenatal Trilogue Play: a new observational assessment tool of the prenatal co-parenting alliance. Infant Mental Health Journal, 27(2), 207-228.

Carter, A. S., Martínez-Pedraza, F. D. L., \& Gray, S. A. (2009). Stability and individual change in depressive symptoms among mothers raising young children with ASD: Maternal and child correlates. Journal of Clinical Psychology, 65(12), 1270-1280.

Cohen, J. (1988). Statistical power analysis for the behavioral sciences. 2nd ed. Hillsdale, NJ: Lawrence Earlbaum Associates.

Curran, P. J., West, S. G., \& Finch, J. F. (1996). The robustness of test statistics to nonnormality and specification error in confirmatory factor analysis. Psychological Methods, 1(1), 16-29.

Davis, N. O., \& Carter, A. (2008). Parenting stress in mothers and fathers of toddlers with autism spectrum disorders: associations with child characteristics. Journal of Autism and Developmental Disorders, 38, 1278-1291.

Duvekot, J., Leontine, W., Slappendel, G., van der Ende, J., Verhulst, F. C., van der Sijde, A., \& Greaves-Lord, K. (2017). Design and cohort characteristics of the social spectrum study: a multicenter study of the autism spectrum among clinically referred children. Journal of Autism and Developmental Disorders, 47(1), 33-48.

Dykens, E. M. (2015). Family adjustment and interventions in neurodevelopmental disorders. Current Opinion in Psychiatry, 28(2), 121.

Ekas, N. V., Lickenbrock, D. M., \& Whitman, T. L. (2010). Optimism, social support, and well-being in mothers of children with autism spectrum disorder. Journal of Autism and Developmental Disorders, 40(10), 1274-1284.

Favez, N., Frascarolo, F., Carneiro, C., Montfort, V., Corboz Warnery, A., \& Fivaz Depeursinge, E. (2006). The development of the family alliance from pregnancy to toddlerhood and children outcomes at 18 months. Infant and Child Development, 15(1), 59-73.

Favez, N., Lopes, F., Bernard, M., Frascarolo, F., Lavanchy Scaiola, C., Corboz Warnery, A., \& Fivaz Depeursinge, E. (2012). The development of family alliance from pregnancy to toddlerhood and child outcomes at 5 years. Family Process, 51, 542-556.

Fishman, I. I., Keown, C. L., Lincoln, A. J., Pineda, J. A., \& Müller, R. A. (2014). Atypical cross talk between mentalizing and mirror neuron networks in autism spectrum disorder. JAMA Psychiatry, $71,751-760$.

Fivaz Depeursinge, E., \& Corboz Warnery, A. (1999). The primary triangle. a developmental systems view of mothers, fathers and infants. New York: Basic Books.

Fivaz Depeursinge, E., \& Favez, N. (2006). Exploring triangulation in infancy: two contrasted cases. Family Process, 45(1), 3-18.

Fivaz Depeursinge, E., Favez, N., Frascarolo, F., (2004). Threeso me intersubjectivity in infancy: A contribution to the development of self-awareness. In: D. Zahavi, T. Grünbaum, J. Parnas, (Eds.), The structure and development of self-consciousness: interdisciplinary perspectives. Vol. 59 (pp. 221-234) Amsterdam, Philadelphia: John Benjamins Publishing. .

Fivaz Depeursinge, E., \& Philipp, D. (2014). The baby and the couple. Understanding and treating young families. London: Routledge.

Fonagy, P., Steele, M., Steele, H., Moran, G. S., \& Higgitt, A. C. (1991). The capacity for understanding mental states: The reflective self in parent and child and its significance for security of attachment. Infant Mental Health Journal, 12(3), 201-218. 
Fonagy, P., \& Target, M. (1997). Attachment and reflective function: Their role in self-organization. Development and Psychopathology, 9(04), 679-700.

Frith, U. (1996). Social communication and its disorder in autism and Asperger syndrome. Journal of Psychopharmacology, 10(1), 48-53.

Gau, S. S. F., Chou, M. C., Chiang, H. L., Lee, J. C., Wong, C. C., Chou, W. J., \& Wu, Y. Y. (2012). Parental adjustment, marital relationship, and family function in families of children with autism. Research in Autism Spectrum Disorders, 6(1), 263-270.

Giallo, R., Wood, C. E., Jellett, R., \& Porter, R. (2013). Fatigue, well being and parental self-efficacy in mothers of children with an autism spectrum disorder. Autism, 17(4), 465-480.

Griffith, G. M., Hastings, R. P., Petalas, M. A., \& Lloyd, T. J. (2015). Mothers' expressed emotion towards children with autism spectrum disorder and their siblings. Journal of Intellectual Disability Research, 59(6), 580-587.

Hastings, R. P., \& Brown, T. (2002). Behaviour problems of children with autism, parental self-efficacy, and mental health. American Journal on Mental Retardation, 107(3), 222-232.

Hoefman, R., Payakachat, N., van Exel, J., Kuhlthau, K., Kovacs, E., Pyne, J., \& Tilford, J. M. (2014). Caring for a child with autism spectrum disorder and parents' quality of life: application of the CarerQol. Journal of Autism and Developmental Disorders, 44 (8), 1933-1945.

Hoffman, C. D., Sweeney, D. P., Hodge, D., Lopez-Wagner, M. C., \& Looney, L. (2009). Parenting stress and closeness: Mothers of typically developing children and mothers of children with autism. Focus on Autism and Other developmental disabilities, 24 (3), 178-187.

Hollingshead, A. A. (1975). Four-factor index of social status. New Haven, CT: Yale University. Unpublished manuscript.

Kasari, C., Sigman, M., Mundy, P., \& Yirmiya, N. (1990). Affective sharing in the context of joint attention interactions of normal, autistic, and mentally retarded children. Journal of Autism and Developmental Disorders, 20(1), 87-100.

Karst, J. S., \& Van Hecke, A. V. (2012). Parent and family impact of autism spectrum disorders: a review and proposed model for intervention evaluation. Clinical Child and Family Psychology Review, 15(3), 247-277.

Kelly, A. B., Garnett, M. S., Attwood, T., \& Peterson, C. (2008). Autism spectrum symptomatology in children: the impact of family and peer relationships. Journal of Abnormal Child Psychology, 36(7), 1069.

Laghi, F., Lonigro, A., Pallini, S., Gradilone, A., Bechini, A., Marziano, G., \& Baiocco, R. (2018). Sibling relationships and family functioning in siblings of early adolescents, adolescents and young adults with Autism Spectrum Disorder. Journal of Child and family Studies, 27(3), 793-801.

Lonigro, A., Baiocco, R., Baumgartner, E., Sette, S., \& Laghi, F. (2017). Persuasion in school-aged children: How does it change if the persuade is the mother or a peer? Cognitive Processing, 18, $67-74$.

Libero, L. E., Maximo, J. O., Deshpande, H. D., Klinger, L. G., Klinger, M. R., \& Kana, R. K. (2014). The role of mirroring and mentalizing networks in mediating action intentions in autism. Molecular Autism, 5, 50.

Lord, C., Risi, S., Lambrecht, L., Cook, Jr., E. H., Leventhal, B. L., DiLavore, P. C., Pickles, A., \& Rutter, M. (2000). The autism diagnostic observation schedule-generic: a standard measure of social and communication deficits associated with the spectrum of autism. Journal of Autism and Developmental Disorders, 30, 205-223.

Lord, C., Wagner, A., Rogers, S., Szatmari, P., Aman, M., \& Charman, T., et al. (2005). Challenges in evaluating psychosocial interventions for autistic spectrum disorders. Journal of Autism and Developmental Disorders, 35(6), 695-708.

Losh, M., Childress, D., Lam, K., \& Piven, J. (2008). Defining key features of the broad autism phenotype: a comparison across parents of multiple-and single- incidence autism families. American Journal of Medical Genetics Part B: Neuropsychiatric Genetics, 147(4), 424-433.

Malagoli Togliatti, M., \& Mazzoni, S. (2006). Osservare, valutare e sostenere la relazione genitori-figli. Il Lausanne Trilogue Play Clinico LTPC. Milano: Raffaello Cortina Editore.

Marcu, I., Oppenheim, D., \& Koren-Karie, N. (2016). Parental insightfulness is associated with cooperative interactions in families with toddlers. Journal of Family Psychology, 30(8), 927.

Marsh, L. E., \& Hamilton, A. F. D. C. (2011). Dissociation of mirroring and mentalising systems in autism. NeuroImage, 56(3), 1511-1519.

McHale, J. (2007). Charting the Bumpy Road of Coparenthood: Understanding the challenges of family life. Washington, DC: Zero To Three.

McHale, J., Fivaz Depeursinge, E., Dickstein, S., Robertson, J., \& Daley, M. (2008). New evidence for the social embeddedness of infants' early triangular capacities. Family Process, 47(4), 245-263.

Minuchin, S. (1974). Families and Family Therapy. Cambridge, Mass.: Harvard University Press.

Montes, G., \& Halterman, J. S. (2007). Psychological functioning and coping among mothers of children with autism: A populationbased study. Pediatrics, 119(5), e1040-e1046.

Oberman, L., \& Ramachandran, V. (2007). The simulating social mind: the role of the mirror neuron system and simulation in the social and communicative deficits of autism spectrum disorders. Psychological Bulletin, 133, 310-327.

Oppenheim, D., \& Koren-Karie (2013). The insightfulness assessment: Measuring the internal processes underlying maternal sensitivity. Attachment and Human Development, 15(5-6), 545-561.

Oppenheim, D., Koren-Karie, N., Dolev, S., \& Yirmiya, N. (2009). Maternal insightfulness and resolution of the diagnosis are associated with secure attachment in preschoolers with autism spectrum disorders. Child Development, 80(2), 519-527.

Phelps, R., Nickel, R., Eisert, D., \& Stein, M. T. (2013). Parental influence on a child's autistic traits. Journal of Developmenta $l$ and Behavioral Pediatrics, 34, 730-732.

Pottie, C. G., \& Ingram, K. M. (2008). Daily stress, coping, and wellbeing in parents of children with autism: a multilevel modeling approach. Journal of Family Psychology, 22(6), 855.

Rao, P. A., \& Beidel, D. C. (2009). The impact of children with highfunctioning autism on parental stress, sibling adjustment, and family functioning. Behavior Modification, 33(4), 437-451.

Rogers, S., Dawson, G., \& Vismara, L. A. (2012). ). An early start for your child with autism: using everyday activities to help kids connect, communicate, and learn. New York: The Guilford Press.

Rutgers, A. H., Bakermans-Kranenburg, M. J., Ijzendoorn, M. H., \& Berckelaer-Onnes, I. A. (2004). Autism and attachment: a metaanalytic review. Journal of Child Psychology and Psychiatry, 45 (6), 1123-1134.

Sigman, M., \& Ruskin, E. (1999). Continuity and change in the social competence of children with autism, Down syndrome, and developmental delays. Monographs of the Society for Research in Child Development, 64 (1) 1-114.

Stern, D. N. (1985). The interpersonal world of the infant. New York: Basic Books.

Sucksmith, E., Roth, I., \& Hoekstra, R. A. (2011). Autistic traits below the clinical threshold: re-examining the broader autism phenotype in the 21st century. Neuropsychology Review, 21(4), 360-389. 
Taylor, J. L., \& Warren, Z. E. (2012). Maternal depressive symptoms following autism spectrum diagnosis. Journal of Autism and Developmental Disorders, 42(7), 1411-1418.

Trevarthen, C., \& Aitken, K. J. (2001). Infant intersubjectivity: research, theory and clinical applications. Journal of Child Psychology and Psychiatry, 42(1), 3-48.

Van IJzendoorn, M. H., Rutgers, A. H., Bakermans-Kranenburg, M. J., Swinkels, S. H., Van Daalen, E., \& Dietz, C., et al. (2007). Parental sensitivity and attachment in children with autism spectrum disorder: Comparison with children with mental retardation, with language delays, and with typical development. Child Development, 78(2), 597-608. van Steijn, D., Oerlemans, A. M., van Aken, M., Buitelaar, J., \& Rommelse, N. (2014). The reciprocal relationship of ASD, ADHD, depressive symptoms and stress in parents of children with ASD and/or ADHD. Journal of Autism and Developmental Disorders, 44, 1064-1076.

Vivanti, G., Prior, M., Williams, K., \& Dissanayake, C. (2014). Predictors of outcome in autism early intervention: why don't we know more? Frontiers in Pediatrics, 2, 58.

Wynne, L. C. (1984). The epigenesis of relational systems: A model for understanding family development. Family Process, 23(3), $297-318$. 